\title{
SITUAÇÃO DE UM SERVIÇO DE SAÚDE PÚBLICA DE FORTALEZA: REALIDADE VIVENCIADA PELO ENFERMEIRO
}

\author{
THE SITUATION OF A PUBLIC HEALTH SERVICE IN FORTALEZA: THE \\ REALITY EXPERIENCED BY NURSES IN THEIR DAILY WORK \\ LA SITUACIÓN DE UN SERVICIO DE SALUD PÚBLICA DE FORTALEZA: \\ LA REALIDAD VIVIDA POR EL ENFERMERO EN SU TRABAJO DIARIO
}

Janaina de Vasconcelos Medeiros ${ }^{1}$

Maria Salete Bessa Jorge ${ }^{2}$

\begin{abstract}
RESUMO: O presente estudo tem como objetivo buscar compreender como os enfermeiros percebem o atual momento na saúde pública. A pesquisa é do tipo qualitativa, de natureza descritiva, critica e analitica. Foi realizada no periodo de junho de 1999 a setembro de 2000, em um hospital da rede pública de Fortaleza. Fizeram parte deste estudo 30 enfermeiros. 19 aceitaram participar do estudo, 8 se recusaram não respondendo o questionário e 3 estavam afastados por licença. Optou-se por trabalhar com questionário e entrevistas de aprofundamento. Como pressupostos de análise, utilizamos a análise de conteúdo. Concluimos que os enfermeiros experimentam uma "catarse" de sentimentos, a partir do momento em que se percebem enquanto trabalhadores de saúde, inseridos no contexto da saúde pública. Finalmente, os enfermeiros se referem às contribuiçōes dadas no sentido de melhorar a sua atuação no serviço de saúde pública, considerando o quadro atual de saúde no Pais.
\end{abstract}

PALAVRAS-CHAVE: Enfermagem, saúde pública ,serviços de saúde, pesquisa qualitativa

\section{INTRODUÇÃO}

\section{OBJETO DE ESTUDO}

A enfermagem, enquanto profissão socialmente reconhecida e formalmente legalizada, vem sendo construida ao longo do tempo e é resultado de muitas lutas e conquistas de seus agentes, isto é, ela é determinada historicamente. Segundo Sena-Chompré e Egry (1998, p. 51), "essa determinação se evidencia em seu pensar, em seu fazer e em suas relações com as concepçōes objetivas e os principios de cada sociedade em que está inserida."

A gênese da enfermagem foi objeto de estudo de vários autores, no entanto, a sua história continua sendo construida a cada dia e é responsabilidade de cada profissional continuar realizando estudos com objetivo de melhor caracterizar o trabalho da enfermagem, bem como a sua articulaçăo com os outros trabalhadores de saúde, sobretudo, a sua contribuiçăo diante deste momento de crise e reestruturação no setor de saúde, momento oportuno para que as profissöes repensem as suas propostas filosóficas de assistência e transformem as suas práticas.

Corroborando com a idéia acima, Donnangelo (1979, p. 84) refere:

\footnotetext{
' Enfermeira do HNC. Fortaleza.

${ }^{2}$ Enfermeira, Dra. em Enfermagem, professora da UECE.
} 


\begin{abstract}
...enquanto que para a área da saúde como um todo multiplicam-se atualmente, em ritmo acelerado, as questōes capazes de orientar novas pesquisas, a área da enfermagem permanece relativamente intocada. Surpreende-me mesmo a impressão de que em momentos anteriores apareciam com maior freqüências questōes referentes à situação da enfermagem na estrutura de produção dos serviços, a sua participação na estrutura de poder dos hospitais, a delimitação dos seus dominios de conhecimento, à legitimaçāo de seus campos de prática. Parece-me que tendem atualmente a escassear as pesquisas sistemáticas sobre a enfermagem e que isto se relaciona à intermitência na discussão acerca do significado e do poder desta profissão na estrutura de saúde.
\end{abstract}

A grave crise social, econômica, politica e moral que atinge os diversos setores da sociedade repercute no âmbito da saúde, com consequêencias na qualidade da assistência que está sendo prestada à população.

A enfermagem, inserida neste contexto, também enfrenta dificuldades no tocante ao seu objetivo, que é prestar assistência integral ao individuo e à comunidade, o que não está sendo possivel diante do quadro de sucateamento do setor saúde. Portanto se questiona: como está sendo prestada essa assistência e qual a contribuição do enfermeiro para este momento na saúde?

Atualmente, a enfermagem vem passando por dificuldades na identificação de seu papel na sociedade, resultado do sucateamento da assistência à saúde, desde 1989, quando o governo federal resolveu deixar em segundo plano a área da saúde no conjunto da seguridade social, fazendo com que as atividades em enfermagem, apesar de mal remuneradas, fossem bastante cobradas.

Segundo Chianca (1994, p. 52),"A solução para a crise do sistema de atenção à saúde no Brasil só pode ser solucionada se todos os elementos da sociedade se envolverem com vontade politica e colaborarem entre si, criando uma dinâmica politica capaz de superar a privatizaçăo e burocratização do SUS. É preciso, acima de tudo, superar a postura alienada e comodista da maioria dos profissionais de saúde, entre os quais os enfermeiros, diante da luta pela Reforma Sanitária."

Diante das consideraçöes, traçou-se como objetivos da investigação: de Fortaleza.

Compreender como os enfermeiros percebem o serviço de saúde pública do municipio

- Analisar como está sendo e como poderia ser a atuação dos enfermeiros de um hospital da rede pública do municipio de Fortaleza.

Mapear as contribuições que os enfermeiros de um hospital da rede pública do municipio de Fortaleza estäo dando, considerando o atual momento na saúde.

\title{
METODOLOGIA
}

A pesquisa é do tipo qualitativa, de natureza descritiva, critica e analitica, no sentido de buscar respostas para atingir os objetivos traçados. Foi realizada no periodo de junho de 1999 a setembro de 2000 , em um hospital da rede pública do municipio de Fortaleza, pertencente à Secretaria Regional $\mathrm{V}$ e situado a oeste de Fortaleza. Fizeram parte desta pesquisa os enfermeiros da unidade de saúde em estudo que aceitaram participar, num total de 30 enfermeiros nos três turnos, destes, 19 aceitaram participar do estudo, 8 se recusaram, não respondendo ao questionário e 3 estavam afastadas por licença maternidade. Optou-se por trabalhar com questionário e entrevista de aprofundamento. O roteiro de entrevista foi construído após uma pré-análise dos dados obtidos pelo questionário.

Depois de coletados, os dados foram analisados tendo como ponto de partida a análise de conteúdo de Bardin (1979), a qual se configura com leituras flutuantes e várias releituras, até 
que sejam encontrados alguns pontos convergentes que serão sintetizados em significados, denominados categorias, analisadas à luz da literatura e da experiência da autora.

\section{RESULTADOS E COMENTÁRIOS}

\section{OS SERVIÇOS DE SAÚDE PÚBLICA: A REALIDADE NA PERCEPÇÄO DOS ENFERMEIROS}

\section{O olhar do enfermeiro sobre a situação de saúde}

\section{Crise na saúde}

Essa categoria empírica trata do olhar multifacetado dos enfermeiros sobre os serviços de saúde no município de Fortaleza. Nesta perspectiva o enfermeiro concebe os serviços de saúde vivenciando momentos de crises, momentos estes caracterizados como "bola de neve", "caos" e outros gerando, assim, insatisfação, baixa produtividade e descrédito. Dessa forma, vem à tona que as politicas de saúde năo satisfazem o desejo dos trabalhadores de saúde. Essa situação se torna evidenciada nos discursos:

Percebo esse momento de crise como uma "bola de neve" que a cada dia aumenta seu volume de problemas, insatisfações e preocupações. (Enfermeira 1)

A crise é um problema que existe há muito tempo, sem resolução, pela falta de interesse do governo federal. (Enfermeira 3)

A convergência das falas, a seguir, revela a situação de saúde, no municipio de Fortaleza, percebida pelos entrevistados que vivenciam, no seu cotidiano de trabalho, situaçöes que refletem o atual momento na saúde. Para os entrevistados, a saúde passa por um momento dificil, conceituado pela maioria como de "crise". Nestes discursos, percebe-se que há um consenso no que diz respeito ao descaso pela saúde pública por parte dos dirigentes, evidenciado pela falta de financiamento, pelo agravamento das condiçöes de saúde da populaçăo e pela crescente demanda reprimida.

\section{Reestruturação dos serviços}

Refere-se à maneira como os entrevistados vêem a tendência de reestruturação dos serviços de saúde, segundo os principios e pressupostos do Sistema Único de Saúde. Mendes (1996) aponta para uma tendência universal de reforma na saúde, com rumos e pressupostos diferentes em determinados paises.Para ele cinco aspectos têm que ser considerados no momento da análise das reformas sanitárias: o processo, o objeto, o conteúdo, o sentido e a inspiração.

Considerando o processo, existem duas maneiras de reforma: as reformas processuais e as discretas (significado estatistico). As reformas processuais são antecedidas por um diagnóstico da crise, possibilitando a criação de proposições que serão levadas a uma ampla discussão com a sociedade, para ,só então, serem transformadas em lei, portanto exigem muito tempo. Já as reformas discretas, apesar de ter como base o diagnóstico da crise, as propostas são criadas por um pequeno grupo com conhecimento técnico sobre o assunto e não são levadas para uma discussão com a sociedade.

Nos discursos dos enfermeiros, uma fala demonstrou a credibilidade nas reformas processuais no momento em que se sente a necessidade de se levar as propostas para uma discussão com a sociedade, vejamos: 
A reestruturação precisa passar por uma discussão com a sociedade de um novo modelo de assistência, onde possa melhorar as condições de atendimento. (Enfermeira 5)

Considerando o aspecto objeto nas reformas sanitárias, o Brasil toma como referência a matriz quebequense, portanto visa um melhor uso dos recursos escassos, uma mudança radical do modelo de atenção e a construção da cidadania (Mendes, 1996)

No que se refere ao conteúdo, a Reforma Sanitária Brasileira está orientada pelos direitos dos cidadăos, na descentralização, na promoção da saúde, na prevenção das doenças e na intersetorialidade, sem deixar de lado a racionalização econômica do sistema (Mendes, 1996).

Percebe-se, no conteúdo das falas dos entrevistados, um total descrédito na reestruturação da saúde no Brasil, relacionado principalmente aos desmandos politicos na área financeira e ao descaso na área da saúde, apesar de se considerar a importância e a necessidade de uma discussão com a sociedade no intuito de criar um novo modelo de atenção à saúde capaz de melhorar o quadro sanitário brasileiro.

Nos discursos anteriores fica evidente que os entrevistados, apesar de perceberem a necessidade de um novo modelo de saúde, não acreditam na possibilidade de isso vir a se concretizar, considerando os grandes desmandos políticos e os diversos interesses que direcionam as politicas de saúde.

\section{Modos de organização dos serviços de saúde deficitários}

O modo de organização dos serviços de saúde em Fortaleza, percebido pelos enfermeiros, não foge ao modelo dominante em todo o pais, ou seja, um modelo que segue as politicas neoliberais, onde a lógica de mercado direciona as politicas públicas do país.

Sistema Único de Saúde: impasses e avanços

Evidencia-se a percepção dos enfermeiros quanto ao Sistema Único de Saúde, como um projeto social decorrente das lutas e conquistas do Movimento Sanitário Brasileiro, que tem pressupostos e princípios com bases socialistas, tendo como principal inovação o conceito de que saúde é um direito do cidadão e um dever do Estado.

O Sistema Único de Saúde (SUS), sistema esse implantado, ou melhor, parcialmente implantado no país, até hoje não chegou a concretizar seus tantos feitos que poderia ocorrer. Seus principios, na sua grande maioria, não são perfeitamente executados. (Enfermeira 1)

Considerando os discursos dos sujeitos sociais da pesquisa, observou-se que os enfermeiros percebem que o Sistema Único de Saúde é resultado de um processo social que vem sendo construido ao longo dos anos e que näo se iniciou e nem terminou em $1988 \mathrm{com}$ a constituição Brasileira, apenas foi consagrada em seus principios e que apesar de se ter alguns avanços, ainda falta muito a ser percorrido para que se alcance a sua totalidade.

\section{Qualidade dos serviços de saúde}

Todas as transformações ocorridas no setor saúde, resultado da Reforma Sanitária Brasileira, deveria ter como conseqüência a melhoria na qualidade da assistência, na resolutividade dos serviços de saúde, na eqüidade e no acesso, porém a falas descritas a seguir revelam que, na prática, essas transformaçőes ainda não acorreram.

Nos discursos que seguem, percebe-se que a população menos provida economicamente é atendida de maneira desigual nos serviços de pronto atendimento, hospitais públicos e postos 
de saúde, onde há uma estrutura fisica deficiente e um número reduzido de materiais e profissionais de saúde, apresentando uma baixa resolutividade.

...filas enormes se formam nos hospitais públicos para atendimento tanto emergencial como ambulatorial, sem um número de profissionais adequado para tal atendimento, $e$ muitas vezes esse atendimento não é de boa qualidade. (Enfermeira 2)

Percebe-se que nos discursos dos enfermeiros fica evidente a percepção de uma baixa qualidade dos serviços de saúde oferecidos pela rede pública do Municipio.

Crise do modelo de atenção médico hospitalar

Mendes (1996, p. 70) se refere ao "caos da saúde" como uma critica que se faz ao SUS e relaciona a uma crise dos serviços de atenção médica, que se manifesta na desorganização dos hospitais e dos ambulatórios. Em algumas das falas das enfermeiras essa situação é retratada, como pode ser constatado a seguir:

Superlotações, emergências lotadas, clientes com estado geral comprometido, filas, espera, tumultos, falta de medicamentos essenciais para dispensação são alguns dos muitos problemas que esta instituição pública possui... (Enfermeira 1)

Para Mendes (1196, p. 70), todos esses problemas não surgiram com o SUS, e são, portanto, problemas históricos em nosso pais, reflexos da crise do Estado e do paradigma flexneriano da atenção médica e foram agravados com o SUS, devido à diminuição do financiamento das ações médicas.

Não dá para se negar que a atenção médica passa por uma crise, principalmente no atendimento hospitalar e isso é motivo de sensacionalismo para a mídia brasileira, que faz com que a notícia se transforme em espetáculo (Mendes, 1996).

Resolutividade do serviço

Retrata a maneira como a resolutividade do serviço é percebida pelos enfermeiros no seu cotidiano de trabalho.

É um momento delicado, porque mesmo sem condições ideais, temos que atender uma grande demanda de pacientes com patologias diversas e graves, onde a maior dificuldade é a referência para encaminhamento dos mesmos. (Enfermeira 4)

Percebe-se, nesses discursos, que o sistema de saúde pública não tem capacidade resolutiva, já que o sistema de referência e contra-referência não funciona na prática, isto é, não se consegue encaminhar pacientes para um serviço de saúde de maior complexidade, quando necessário, porque o sistema não tem capacidade de atender a excessiva demanda.

Humanização na assistência

A percepção dos enfermeiros quanto ao relacionamento cliente-profissional de saúde no serviço de saúde pública é retratada nos discursos abaixo:

Pessoas mendigam um atendimento e na maioria das vezes são maltratadas, existe falta de humanização nos atendimentos. (Enfermeira 2) 
Situação de um serviço de saúde pública...

Os discursos acima são contraditórios, enquanto a enfermeira tenta, apesar das condições citadas, prestar uma assistência humanizada, os usuários se deparam com serviços de saúde pública, onde são tratados de maneira impessoal e onde sua única identidade é a patologia ou queixa de saúde fica evidenciado pela relaçăo de poder que se estabelece entre o profissional e o usuário do serviço.

Ética na saúde

Refere-se à importância dada pelos enfermeiros às questões éticas direcionadas ao relacionamento cliente-profissional de saúde e de que forma elas interferem ou contribuem na qualidade dos serviços prestados pelo sistema de saúde pública.

Responsabilidade, assiduidade, pontualidade, atenção e respeito ao usuário, são alguns pontos que considero muito importantes para desempenho de minhas tarefas. (Enfermeira1)

Nesses discursos, percebe-se a consciência por parte dos enfermeiros da importância de algumas caracteristicas pessoais ou qualidades adquiridas na atuação profissional, evidenciando o compromisso profissional com a ética como uma ferramenta capaz de amenizar os problemas vivenciados nos serviços de saúde pública.

\section{COMO O ENFERMEIRO SE PERCEBE NO CONTEXTO DA SAÚDE.}

Nessa categoria, evidencia-se o modo como os enfermeiros se percebem enquanto trabalhadores de saúde, inseridos no contexto da saúde pública e nesta autopercepção, exteriorizam sentimentos diversos, como insatisfação, impotência, descrédito e outros que geram sofrimento psicológico.

\section{Insatisfaçöes}

Trata dos sentimentos evidenciados nos discursos dos enfermeiros, enquanto estes se percebem no contexto de trabalho nos serviços públicos de saúde.

A minha atuação está prejudicada, pois com o número de profissionais reduzidos, o meu desempenho fica limitado e a atenção dispensada aos pacientes graves. (Enfermeira 17).

A forma como os enfermeiros exteriorizam insatisfaçăo demonstra que esse sentimento está relacionado à forma de gerenciamento dos serviços de saúde. Portanto o local de trabalho é considerado desfavorável ao desenvolvimento de atividades profissionais, desencadeando sentimentos de insatisfaçăo nos mesmos.

\section{Impotência}

A categoria empirica "impotência" se refere ao conteúdo revelado nos discursos dos enfermeiros que demonstram o sentimento de incapacidade na resolutividade dos problemas do seu cotidiano profissional.

...Às vezes, sentimo-nos incapazes diante de situações que não dependem mais de nós como enfermeiros, mas do sistema de saúde disponivel. (Enfermeira 19)

Nesses discursos, fica evidente que, ao tomar contato com os seus sentimentos, os 
enfermeiros, no exercicio profissional, percebem-se impotentes no manejo de suas atribuições por problemas que fogem a sua capacidade profissional e dizem respeito à forma de organização dos serviços de saúde pública.

\section{Limitações}

Essa categoria trata de mais um sentimento desvelado nos discursos no momento em que os enfermeiros se percebem, enquanto trabalhadores de saúde, inseridos no contexto da saúde pública:

Procuro atuar de maneira mais eficiente, dentro de nossas limitações. (Enfermeira 1)

Percebe-se que a limitação citada nos discursos está relacionada a problemas no gerenciamento dos serviços de saúde, como indefinição de papéis, demanda excessiva e falta de materiais e equipamento essenciais.

\section{Gerenciamento dos serviços de saúde}

Observa-se a percepção dos enfermeiros no que se refere ao gerenciamento dos serviços de saúde pública. Nos discursos que seguem, percebe-se que os enfermeiros consideram os recursos humanos e materiais insatisfatórios, o que influencia diretamente na qualidade dos serviços prestados.

Procurando ser sempre o mais profissional possivel apesar das condições oferecidas. (Enfermeira 4)

No meio do quadro caótico, como a falta de recursos humanos, materiais e de uma politica administrativa séria, tento prestar uma assistência humanizada, exaltando o real valor do cliente, tornando-o sujeito do processo saúde-doença. (Enfermeira 6)

A minha atuação está prejudicada, pois com o número de profissionais reduzidos, o meu desempenho fica limitado e a atenção dispensada aos pacientes graves. (Enfermeira 17)

\section{Política de recursos humanos insatisfatória}

Refere-se à maneira como os participantes do estudo se percebem, enquanto pertencentes ao quadro de recursos humanos da instituição; bem como à forma como se sentem prejudicados pela falta de um politica de recursos humanos que os valorize e dê melhores condições de trabalho aos profissionais de saúde.

No meio do quadro caótico, como a falta de recursos humanos, materiais e de uma politica administrativa séria, tento prestar uma assistência humanizada, exaltando o real valor do cliente, tornando-o sujeito do processo saúde-doença. (Enfermeira 6)

Como conseqüência, apontam vários problemas que interferem diretamente na qualidade dos serviços prestados, tais como: indefinição de papéis, número insuficiente de profissionais, acomodação, dentre outros.

Nosso trabalho fica comprometido, porque muitas vezes fazemos o serviço do auxiliar de enfermagem, não temos um quadro bom de auxiliares. (Enfermeira 2) ....ainda temos dificuldade com a questão da definição de papéis: acumulamos funções que deveriam ser desempenhadas por outros profissionais "em nome do 
paciente. (Enfermeira 8)

Percebe-se que a indefinição de papéis é resultado da falta de uma politica de valorização dos recursos humanos em que os enfermeiros acabam tendo que assumir outras funções dentro da instituição onde trabalham, visando melhorar a qualidade da assistência prestada, gerando, portanto, insatisfação e desgaste profissional.

\title{
PROPOSTAS ALTERNATIVAS
}

Percebe-se nas falas dos enfermeiros a valorização da reciclagem no quadro de recursos humanos da instituição em todas as categorias e em todos os niveis de escolaridade.

Outro ponto considerado importante dentro das contribuiçőes é a prestação de uma assistência de qualidade e humanizada, priorizando o atendimento aos pacientes mais graves, com a implementação da metodologia da assistência de enfermagem, oportunizando esse atendimento com orientações sobre educação em saúde e sobre noções de cidadania.

A utilização da ética na saúde, em todas as fases do atendimento ao usuário no serviço de saúde, foi também evidenciada em quase todos os discursos.

Outra questão levantada foi a participação em reuniões de classe e grupos de estudo dentro da instituição, momentos oportunos para o questionamento das formas de assistência prestada e para sugestões no sentido de superar as dificuldades do cotidiano de trabalho; objetivando com isso a prestação de uma assistência de qualidade, humanizada, compromissada com os preceitos éticos e com a valorização da cidadania de cada usuário do serviço de saúde.

\section{CONSIDERAÇÕES FINAIS}

Depois de finalizadas todas as etapas, a reflexão que pode ser feita é que os enfermeiros vivenciam diversas situações que caracterizam a crise na saúde pública.

Através deste estudo, percebe-se que os enfermeiros experimentam uma "catarse" de sentimentos, a partir do momento em que se percebem enquanto trabalhadores de saúde, inseridos no contexto da saúde pública, sentimentos esses que variam entre insatisfação, impotência e de limitação.

Diante do foi anteriormente exposto, os enfermeiros se referem às contribuições dadas no sentido de melhorar a sua atuação no serviço de saúde pública, considerando o quadro atual de saúde no País.

\begin{abstract}
The aim of this study is to understand how nurse professionals perceive the present situation of public health. This is a qualitative research, of descriptive, critical and analytical nature. It was carried out from June 1999 until September 2000 in a public hospital in Fortaleza. Thirty nurses were the subjects of this investigation. Nineteen of them accepted to participate in the study, eight refused to answer the questionnaire and three were on a maternity leave. Questionnaires and indepth-interviews were used to collect data. Content analysis was adopted to examine the interviews. It was concluded that nurses have a diversity of feelings in relation to themselves, as health workers, inserted in the public health context. The participants in the investigation also referred to the contributions nurse professionals have given to the public health service in Brazil.
\end{abstract}

KEYWORDS: nursing, public health, public health service, qualitative research

RESUMEN: Este estudio tiene por objetivo comprender la forma como los enfermeros perciben el actual momento en la salud pública. La investigación es de tipo cualitativo, de naturaleza descriptiva, 
critico -analitica. Se realizó durante el periodo de junio de 1999 a septiembre de 2000, en un hospital de la red pública de Fortaleza. Se han incorporado al estudio 30 enfermeros. De ellos, 19 aceptaron y tres estaban de baja. Se optó por trabajar con cuestionarios y entrevistas de profundización. Como presupuestos de análisis, utilizamos el análisis de contenido. Se concluye que los enfermeros experimentan una "catarsis" de sentimientos a partir del momento en que se perciben como trabajadores de la salud, dentro del contexto de la salud pública. Finalmente, los enfermeros se refieren a las contribuciones dadas para mejorar su actuación en los servicios de salud pública, teniendo en cuenta el cuadro actual de la salud en el pais.

PALABRAS CLAVE: enfermeria, salud pública, servicios de salud,investigación cualitativa

\section{REFERÊNCIAS BIBLIOGRÁFICAS}

BARDIN, L. Análise de conteúdo. Lisboa: Ediçōes 70, 1979.

CHIANCA, T. C. M. O Sistema Único de Saúde: A proposta de viabilizaçäo e a inserçäo da enfermagem. Saúde em debate, v.44, set. 1994.

DONNANGELO, M. C. F. In: SEMINÁRIO NACIONAL DE PESQUISA EM ENFERMAGEM. 1., 1979, Ribeirão Preto. Relatório... Ribeirão Preto: ABEn/CEPEn, 1979. p. 82-97.

MENDES, E. V. Uma agenda para saúde. São Paulo: HUCITEC, 1996. 300p.

SENA-CHOMPRÉ, R. R. de; EGRY, E. Y. A construçäo do espaço teórico-político da enfermagem no âmbito da saúde. In: A enfermagem no projeto uni: Redefinindo um novo projeto politico para a enfermagem brasileira. São Paulo: HUCITEC, 1998.

As transformações sócio-econômicas e as repercussōes no setor saúde: Breve retomada histórica. In: _. A enfermagem no projeto uni: redefinindo um novo projeto politico para a enfermagem brasileira. Säo Paulo: HUCITEC, 1998.

Recebido em dezembro de 2000

Aprovado em maio de 2001 